\title{
Experimental techniques of high-resolution inelastic X-ray scattering measurements for supercritical metallic fluids at high temperature and high pressure using synchrotron radiation at SPring-8
}

\author{
M.Inui ${ }^{1}$, D.Ishikawa ${ }^{2}$, K.Matsuda ${ }^{3}$, K. Tamura ${ }^{3}$, A.Q.R.Baron²,4 \\ ${ }^{1}$ Graduate School of Integrated Arts and Sciences, Hiroshima University, Higashi-Hiroshima, Hiroshima \\ 739-8521, Japan \\ 2 SPring-8/RIKEN 1-1-1 Kouto, Sayo-cho, Sayo-gun, Hyogo 679-5148, Japan \\ 3 Graduate School of Engineering, Kyoto University, Kyoto 606-8501, Japan \\ ${ }^{4}$ SPring-8/JASRI 1-1-1 Kouto, Sayo-cho, Sayo-gun, Hyogo 679-5198, Japan
}

Received November 2, 2007

\begin{abstract}
We have conducted high-resolution inelastic X-ray scattering (IXS) measurements of supercritical metallic fluids at high temperature and high pressure using synchrotron radiation at SPring-8 in Japan. We developed a high-pressure vessel for IXS measurements pressurized by He gas up to $196 \mathrm{MPa}$ and installed the highpressure gas apparatus in the experimental hutch. After the installation IXS experiments were carried out for supercritical fluid $\mathrm{Hg}$ to study atomic dynamics in the metal-nonmetal transition near the liquid-vapor critical point. Next the apparatus is used to study atomic dynamics in the semiconductor-metal transition in supercritical fluid Se. In this article we report the experimental technique at high temperature and high pressure in detail, and show recent results using the technique.
\end{abstract}

Key words: supercritical metallic fluid, atomic dynamics, inelastic $X$-ray scattering, high temperature, high pressure, fluid $\mathrm{Hg}$

PACS: $61.25 . M v, 61.10 . E q, 71.30 .+h, 63.50 .+x, 47.35 . R s, 51.40 .+p$

\section{Introduction}

Understanding atomic dynamics in liquids is an important subject in physics in the twenty-first century. Beginning in the middle of the previous century, inelastic neutron scattering (INS) was the probe of choice to study liquid dynamics on atomic length and time scales. Information on collective and individual atomic motions can be obtained from INS by analyzing coherent and incoherent components of the dynamic structure factor, $S(Q, E)$, where $Q$ and $E$ are momentum and energy transfer, respectively. In the last five years of the previous century, it became possible to use x-rays, instead of neutrons, as a probe of atomic dynamics (IXS instead of INS) [1,2], especially in disordered materials [3]. IXS is different from INS in the matter that the incoherent cross-section for x-rays only becomes large at high $(>\mathrm{eV})$ energy transfers due to the small electron mass, so the IXS spectrum is entirely coherent and reflects the collective dynamics. X-ray scattering also offers the advantage of a very small beam size, which can be especially useful for extreme environments, and is not limited by some of the kinematic constraints of neutron scattering, since, generally, the energy transfer $(<0.1 \mathrm{eV})$ is much smaller than the x-ray energy $(\sim 20 \mathrm{keV})$. Thus, IXS is well suited to investigate atomic dynamics under extreme conditions such as high temperature and high pressure.

Liquid metals and semiconductors transform to an insulating state on evaporation. However, an actual metal-nonmetal (M-NM) transition is known to occur in a fluid phase much denser than the vapor phase [4]. To investigate a process of the M-NM transition in metallic fluids, we have to control the density of a fluid. A continuous path of volume expansion from liquid to rarefied 


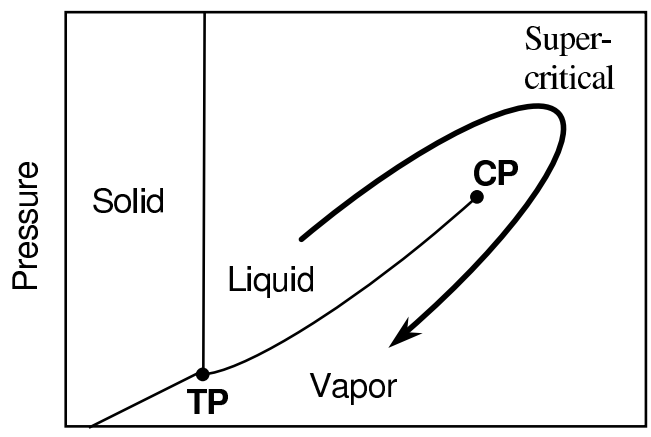

Temperature

Figure 1. A schematic phase diagram on a pressure-temperature plane. TP and CP denotes the triple point and the critical point, respectively.

vapor is possible when the fluid circumnavigates the liquid-vapor critical point without crossing the saturated-vapor-pressure curve, as shown in figure 1. In the expansion process where the mean interatomic distance increases up to ten times larger than that under normal conditions, it is known that a gradual M-NM transition occurs. Liquid $\mathrm{Hg}$, well known as a prototype liquid metal, undergoes such a M-NM transition when the density is reduced to about $9 \times 10^{3} \mathrm{~kg} \mathrm{~m}^{-3}$ near the critical point [5]. Liquid Se, which is the only elemental liquid semiconductor, also experiences a semiconductor-metal-insulator $(\mathrm{SC}-\mathrm{M}-\mathrm{I})$ transition with the volume expansion up to the critical point [6].

It is obvious that information on the atomic arrangement in these metallic fluids is quite important for the understanding of the mechanism of the metal-non-metal (M-NM) transition. However, structural studies such as diffraction experiments of supercritical metallic fluids are not so easy because the critical temperature and pressure are very high compared to those for molecular fluids as indicated in table 1. For many decades there have been almost no structural studies of supercritical metallic fluids except for fluid $\mathrm{Rb}$ and $\mathrm{Cs}$. The static structure factor $S(Q)$ as well as $S(Q, E)$ of fluid $\mathrm{Rb}$ and $\mathrm{Cs}$, whose critical pressures are low compared to that of, namely, fluid $\mathrm{Hg}$, were investigated in the pioneering works of Hensel and co-workers using neutrons [7]. About two decades ago Tamura and Hosokawa developed a high-pressure vessel with Be windows and a specially designed sapphire cell for X-ray diffraction measurements of supercritical fluid $\mathrm{Hg}$ [8]. This technique has been widely applied to a variety of structural studies for metallic fluids at high temperature and high pressure, and the quality of the data has been much improved using synchrotron radiation as seen in the reference [9].

Table 1. The critical constants of several fluids.

\begin{tabular}{|c|c|c|c|}
\hline fluid & $T_{\mathrm{c}}[\mathrm{K}]$ & $p_{\mathrm{c}}[\mathrm{MPa}]$ & $\rho_{\mathrm{c}}\left[\mathrm{kg} \mathrm{m}^{-3}\right]$ \\
\hline \hline $\mathrm{Rb}[10]$ & 2017 & 12.45 & $0.29 \times 10^{3}$ \\
\hline $\mathrm{Cs}[10]$ & 1924 & 9.25 & $0.38 \times 10^{3}$ \\
\hline $\mathrm{Hg}[11]$ & 1751 & 167.3 & $5.8 \times 10^{3}$ \\
\hline $\mathrm{Se}[12]$ & 1888 & 38.5 & $1.85 \times 10^{3}$ \\
\hline $\mathrm{S}[13]$ & 1310 & 20.4 & $0.6 \times 10^{3}$ \\
\hline $\mathrm{H}_{2} \mathrm{O}[14]$ & 647.1 & 22.5 & $0.32 \times 10^{3}$ \\
\hline
\end{tabular}


To get information on atomic dynamics in supercritical metallic fluids, it is essential to carry out high-resolution IXS experiments using a high brilliant X-ray beam generated by the third generation synchrotron radiation facility. Combining our high temperature and high-pressure technique with an appropriate x-ray spectrometer, we have a greater possibility of getting data of high quality on atomic dynamics in supercritical metallic fluids. In this paper we describe the experimental technique under the extreme condition at high temperature and high pressure, using synchrotron radiation at the super-photon ring operating at $8 \mathrm{GeV}$ (SPring-8) in Japan. As examples of the application of the technique, we present the results of supercritical fluid $\mathrm{Hg}$ and a preliminary result of supercritical fluid Se.

\section{High pressure gas apparatus for IXS measurements}

The high-resolution IXS experiments were conducted at the beamline BL35XU of SPring-8 in Japan. The initial design of the beamline is described in reference [15]. In our experimental set-up, backscattering at the Si (11 11 11) reflection was used to provide an incident beam with a $0.8 \mathrm{meV}$ bandwidth onto the sample. The energy of the incident beam and the Bragg angle of the backscattering were $21.747 \mathrm{keV}$ and approximately $89.98^{\circ}$, respectively. The flux of the incident beam on the sample was $3 \times 10^{9}$ photons/sec in the early phase and several improvements make the flux increase up to $4 \times 10^{9}$ photons/sec now. We used only three of the (now) twelve spherical analyzer crystals at the end of the $10 \mathrm{~m}$ horizontal arm due to the restriction of the high-pressure window as described below. Notably, BL35XU is designed to maximize the space around the sample to enable installation of large sample environments. We used space of $340 \mathrm{~mm}$ below the beam, and in fact somewhat more (up to $\sim 400 \mathrm{~mm}$ ) below the beam is available if needed. A large diameter $(270 \mathrm{~mm})$ in the scattering plane was also needed to accommodate the high pressure

(a)

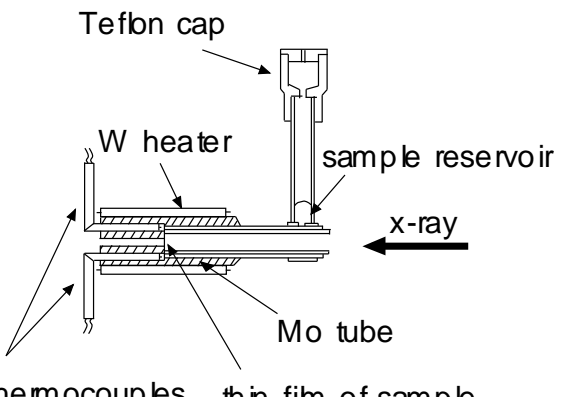

W-Re thermocouples thin fim of sample

$20 \mathrm{~mm}$

(b)

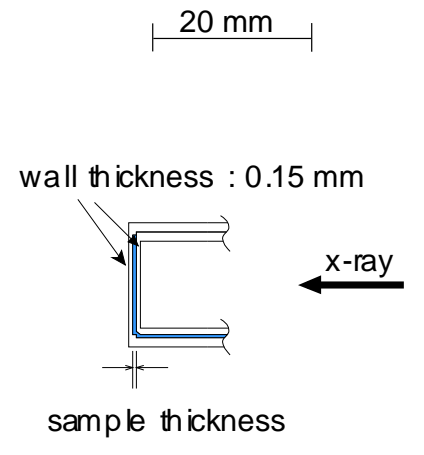

(c)

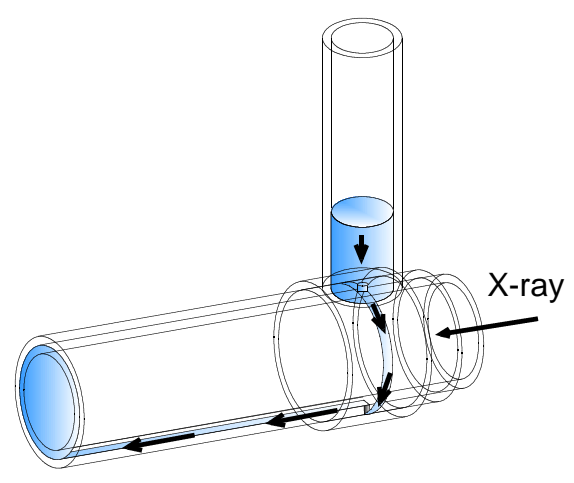

Figure 2. (a) a side-view in section of a sapphire cell of the original design by Tamura. (b) a thin film of the sample and sapphire walls on an enlarged scale. (c) a perspective plot of the cell with the sample path. 
windows, and this, with work, was also possible (see discussion below), though the default size is 120 to $160 \mathrm{~mm}$ diameter. The spectrometer resolution was $1.6-1.8 \mathrm{meV}$ depending on the analyzer crystal as measured using the scattering from polymethyl methacrylate (PMMA).

Supercritical metallic fluids such as $\mathrm{Hg}$ and Se should be contained in a cell made of a special material that is transparent to X-rays and resistant to chemical corrosion by hot metallic fluids. A single-crystal sapphire was chosen for this purpose and Tamura and Hosokawa [8] developed a sapphire cell as illustrated in figure 2 (a). The cell consists of a hot part heated by a surrounding W heater and a sample reservoir kept at around the melting temperature of the liquid sample. Sapphire components were connected with a high-temperature ceramic adhesive (SEM-COM Company Incorporated, type SCE-1) whose melting temperature is approximately $1500 \mathrm{~K}$. The construction around the hot part is shown in figure 2 (b) on an enlarged scale. The thickness of the sapphire wall was $0.15 \mathrm{~mm}$ and the sample space was fixed to give a suitable sample thickness from 0.03 to $1.3 \mathrm{~mm}$. The details of the construction are described in the reference $[9,16]$.

Previously, in measuring X-ray diffraction from the fluid sample contained in the sapphire cell using a white x-ray beam, a problem was how to discriminate many strong Laue spots from the single-crystalline sapphire. The problem was overcome by employing the adjustment of the crystalline axis as described in the reference $[9,16]$. The cell used to measure IXS spectra was made in the same way as the previous one while a monochromatized X-ray beam generates only a few Bragg spots from a single-crystalline sapphire.

We have developed a high-pressure vessel in order to measure IXS spectra of supercritical metallic fluids. The concept of the vessel is that the sample is locally heated above the critical temperature and the pressure is transformed into the hot sample through the liquid surface in the sample reservoir of the cell (see figure $2(\mathrm{c})$ ) when the vessel is filled with compressed He gas. It was

(a)
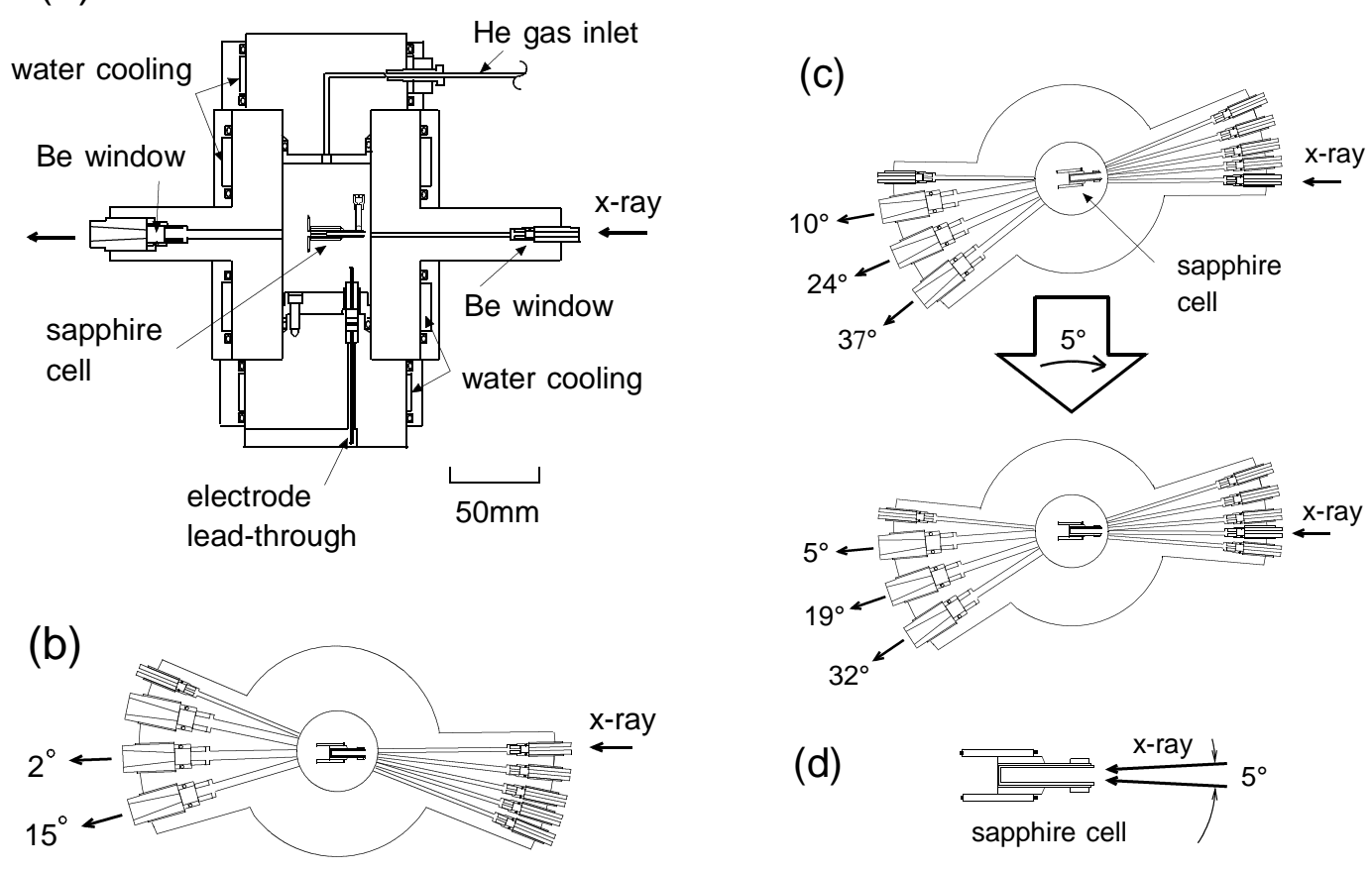

Figure 3. (a) a side-view in section of the high-pressure vessel for IXS experiments. (b) a topview of the high-pressure vessel for IXS measurements at $2 \theta$ of $2^{\circ}$ and $15^{\circ}$. (c) Its top-view for IXS measurements at $2 \theta$ of $10^{\circ}, 24^{\circ}, 37^{\circ}, 5^{\circ}, 19^{\circ}$ and $32^{\circ}$. (d) a top-view in section of the sapphire cell on an enlarged scale. 
hard work to make the high-pressure vessel for our study because we have to obey the Japanese law of high-pressure gas in which Japanese government regulates every kind of high-pressure "gas" apparatus from a huge chemical plant to a small bombe. Then we had to obtain a special permission by the Government agency to make the high-pressure vessel operated at extremely high pressure up to $196 \mathrm{MPa}$.

Figure 3 (a) shows a side-view of the high-pressure vessel for IXS experiments in section. The vessel is composed of the upper and lower flanges and main cylinder, which are made of nickel chromium molybdenum steel. An X-ray beam passes through a Be window of $4 \mathrm{~mm}$ in diameter and $5 \mathrm{~mm}$ in length on the right side of the main cylinder and is incident on the sample at the center of the vessel. Large Be windows of $10 \mathrm{~mm}$ in diameter and $10 \mathrm{~mm}$ in length for scattered $\mathrm{X}$-rays are fixed on the left side of the main cylinder as seen in the figure. High pressure He gas (the purity $>99.999 \%$ ) is loaded from the inlet on the upper flange. The lower flange is equipped with the electrode lead-throughs for heaters and thermocouples. The sapphire cell is held by alumina discs with heating accessories which are not shown in the figure. To seal high pressure He gas in the vessel, rubber O-rings are used for the flanges and Be windows. The seal around the electrode leadthrough is made with Teflon disks with a hole in it. The details of sealing technique are described in the reference [16]. The upper and lower flanges are clamped by a frame made of high tension steel which is not illustrated in the figure.

Figure 3 (b) shows a top-view of the high-pressure vessel. The vessel is equipped with five Be windows for incident X-rays and three large Be windows for scattered ones. A small Be window on the left side is prepared only to monitor the direct beam. The purpose of these Be windows is to cover the observable $Q$ as wide as possible (Here $Q$ is defined by $4 \pi E_{i} \sin \theta / h c$, where $E_{i}$, $2 \theta, h$ and $c$ are the incident energy, the scattering angle, Planck constant and the light velocity, respectively). The aperture of the large Be window is approximately $4^{\circ}$, from which scattered $\mathrm{X}$ rays can irradiate the three analyzer crystals on the horizontal detector arm approximately $10 \mathrm{~m}$ apart from the sample. Using the angle set-up shown in figure 3 (b), we can measure IXS spectra at three $Q$ positions $1.8<Q<4.0 \mathrm{~nm}^{-1}$ and $27<Q<30 \mathrm{~nm}^{-1}$ at around $2 \theta$ of $2^{\circ}$ and $15^{\circ}$, respectively. The large window at $2 \theta=2^{\circ}$ has another purpose of monitoring the direct beam in order to adjust the sample position at the center of the goniometer, and to measure the X-ray transmission of the sample at each thermodynamic condition. To observe IXS spectra at other $Q$ positions, the second angle set-up is needed as shown in figure 3 (c). By the upper set-up of an initial position, we can adjust the sample position by measuring the direct beam through the small Be window, and measure the X-ray transmission of the sample. Using this angle position, observable $Q$ positions are $18<Q<21 \mathrm{~nm}^{-1}, 45<Q<48 \mathrm{~nm}^{-1}$ and $69<Q<72 \mathrm{~nm}^{-1}$ through the large Be windows located at $2 \theta$ of $10^{\circ}, 24^{\circ}$ and $37^{\circ}$, respectively. In this set-up, X-rays are incident on the sample $2.5^{\circ}$ obliquely to the right angle as illustrated in figure 3 (d). After the sample position is adjusted, the sample table is clockwise rotated by $5^{\circ}$ to make the third angle position as seen in the lower set-up in figure 3 (c). $2 \theta$ of each window is displaced by $-5^{\circ}$ and observable $Q$ positions are $9<Q<12 \mathrm{~nm}^{-1}, 36<Q<39 \mathrm{~nm}^{-1}$ and $59<Q<62 \mathrm{~nm}^{-1}$. Although the window positions of the high-pressure vessel are designed to access high $Q$ region at $2 \theta>24^{\circ}$, we have not measured IXS spectra at such high $Q$ for supercritical metallic fluids. An example of the observed $Q$ positions and the static structure factor $S(Q)$ of fluid $\mathrm{Hg}$ at $9 \times 10^{3} \mathrm{~kg} \mathrm{~m}^{-3}$ are shown in figure 4 (a).

The high-pressure vessel described here makes it possible to make measurements on supercritical fluid metals, which is a notable advancement. However, in the spirit of providing the best possible information for the others working in the field, we also discuss some of the limitations of the vessel. The large diameter of the vessel, a result of the high-pressure windows, is not optimal for IXS measurements, which rely on operating very close (within about $0.3 \mathrm{mrad}$ ) to a backscattering geometry in order to preserve good energy resolution. In short, there is a geometric contribution to the energy resolution given by $\Delta E / E=\delta \Delta \Theta$ where $\delta$ is the deviation from backscattering, $\Delta \Theta$ is the angular tolerance (in this case given by the size of the analyzer pixels at $\Delta \Theta=0.6 \mathrm{~mm} / R \approx 6 \times 10^{-4}$ radian, where $R$ is the arm radius of $9.8 \mathrm{~m}$ ). The larger diameter of the vessel forces one to move the detectors about $240 \mathrm{~mm}$ from the sample position, and then, since the beam from the sample is divergent, the detectors should be moved away from backscat- 
(a)

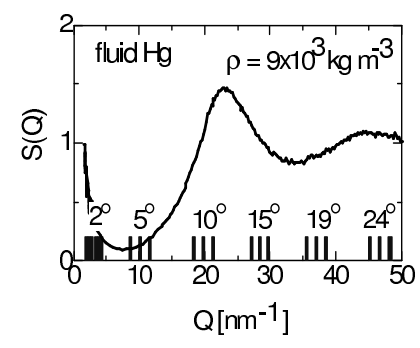

(b)

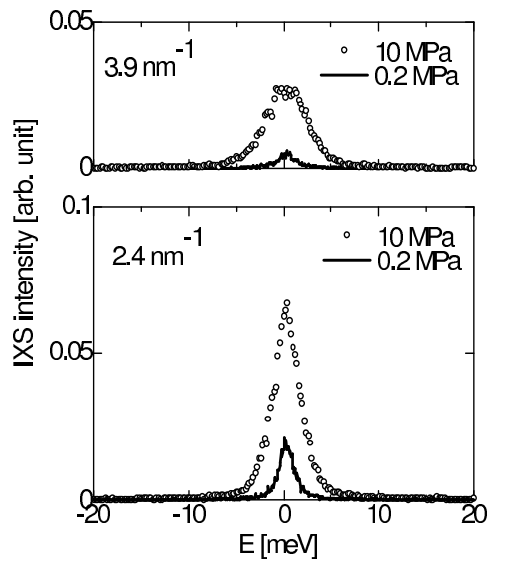

(c)
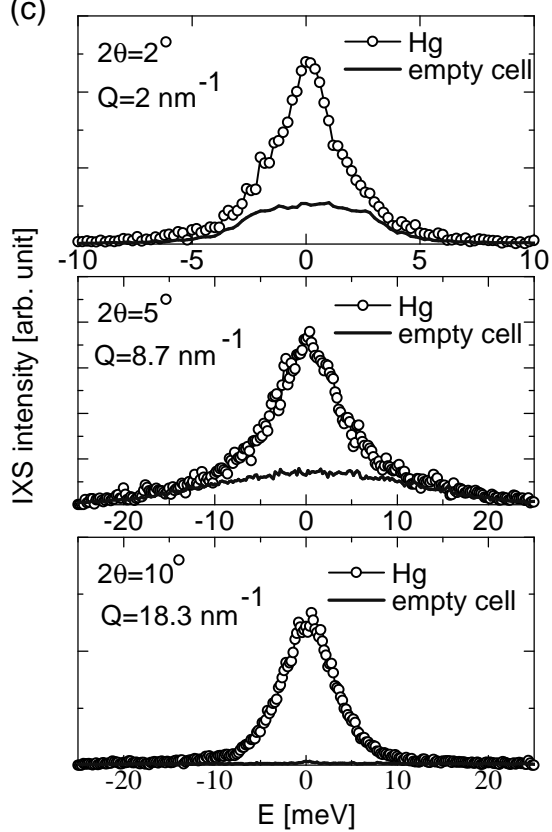

Figure 4. (a) Observable $Q$ positions (bars) at each $2 \theta$ and $S(Q)$ of fluid $\mathrm{Hg}$ at $9 \times 10^{3} \mathrm{~kg} \mathrm{~m}^{-3}$ (solid line) (b) Comparison of background spectra at $0.2 \mathrm{MPa}$ with those $10 \mathrm{MPa}$, measured at $2 \theta=2^{\circ}$ and at the ambient temperature using empty cell. (c) IXS spectra of fluid $\mathrm{Hg}$ at $1723 \mathrm{~K}$ and $193 \mathrm{MPa}$ whose density is approximately $9 \times 10^{3} \mathrm{~kg} \mathrm{~m}^{-3} \cdot 2 \theta$ and $Q$ values are indicated on each panel. Also shown are IXS spectra of empty cell at the same thermodynamic condition after the absorption correction.

tering. Then one can estimate the backscattering angle as $\delta=d / R / 2$, where $d$ is the displacement of the detector from the sample-analyzer axis. Practically, one sees a slight $(\sim 0.1$ to $0.2 \mathrm{meV})$ degradation of the spectrometer resolution. In addition, and sometimes more seriously, the motion of the detectors changes the scattering plane of the analyzers, so that, especially at the $\operatorname{Si}(1111$ 11) reflection, one can pick up a parasitic response at about $9 \mathrm{meV}$ due to simultaneous Bragg scattering [17]. This can be avoided, sometimes, by a judicious choice of detectors (only 3 out of the 12 are used, so one can select which 3 detectors exactly, and thereby modify the scattering plane of the analyzers).

Other experimental difficulties associated with the setup have to do with the relatively small sample volume as compared with the very thick high pressure Be windows and the large path in $\mathrm{He}$. Both the He and the Be create a background at small scattering angles. The peak shown in figure $4(\mathrm{~b})$, at $2 \theta=2^{\circ}$, is mainly derived from polycrystalline Be. It is reduced at $3.9 \mathrm{~nm}^{-1}$. With the compression at $10 \mathrm{MPa}$, the background is enhanced in both panels: in fact, then, the background from $\mathrm{He}$ gas is more serious in low Q region than the background from the Be. The limitation on the number of analyzer crystals is also awkward, leading to longer data collection times. In fact, the study on supercritical fluid $\mathrm{Hg}$ required about 2 months of beamtime spread over 2 years. While one could expect that both increased experience and beamline improvements might shorten this time if the project were started today, it gives one a feeling for the scale involved in this work.

We compare the signal of fluid $\mathrm{Hg}$ with the background. Figure 4 (c) shows examples of scattering intensity as a function of energy. $2 \theta$ and $Q$ values are indicated in the figure. Black curves with open circles and bold solid lines are IXS intensity of fluid Hg in the M-NM transition region 
and the background at the same thermodynamic condition, respectively. The background spectra measured with an empty cell are shown after being scaled by the sample absorption coefficient. IXS spectra at low $Q$ less than $10 \mathrm{~nm}^{-1}$, large background from the compressed He gas was observed because X-rays scattered from all amount of He gas existing along the X-ray path can contribute to the background at small $2 \theta$. However, the signal from the fluid $\mathrm{Hg}$ is so large in the $\mathrm{M}-\mathrm{NM}$ transition region that we can obtain reasonable data at low $Q$. This result may have been expected from a large small-angle scattering in the M-NM transition region as indicated in figure 4 (a). With increasing $2 \theta$, the total amount of He gas observable from the aperture of the analyzer crystal is reduced. At $2 \theta>10^{\circ}$, the background becomes negligibly small as shown in the figure.

\section{Examples of IXS studies using the present technique}

\subsection{The $\mathrm{M}-\mathrm{NM}$ transition in expanded fluid $\mathrm{Hg}$}

Fluid $\mathrm{Hg}$ undergoes the M-NM transition at $9 \times 10^{3} \mathrm{~kg} \mathrm{~m}^{-3}$. IXS spectra of the fluid $\mathrm{Hg}$ were measured at the thermodynamic states along the saturated vapor pressure curve including the $\mathrm{M}-\mathrm{NM}$ transition region, as indicated by open squares in figure 5 (a) [18]. The spectra were analyzed using the model function constituting the Lorentzian for the quasielastic component and the damped harmonic oscillator (DHO) for the inelastic excitation. Figure 5 (b) shows the fits and the optimized model function at low $Q$ in the M-NM transition. The DHO component in the

(a)

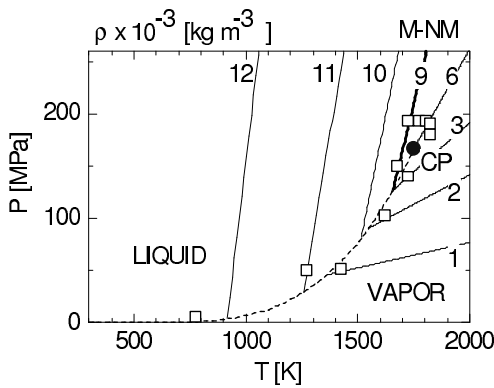

(b)

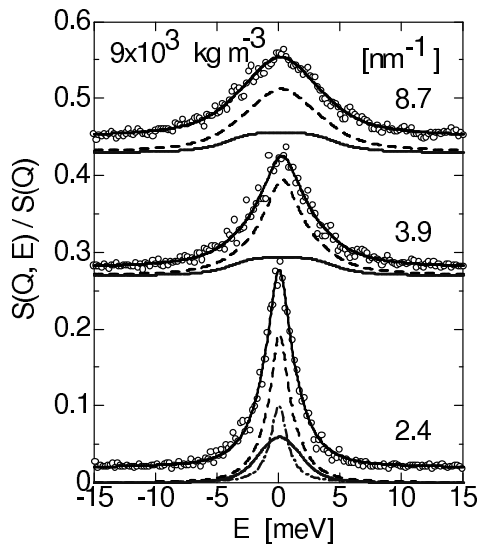

(c)

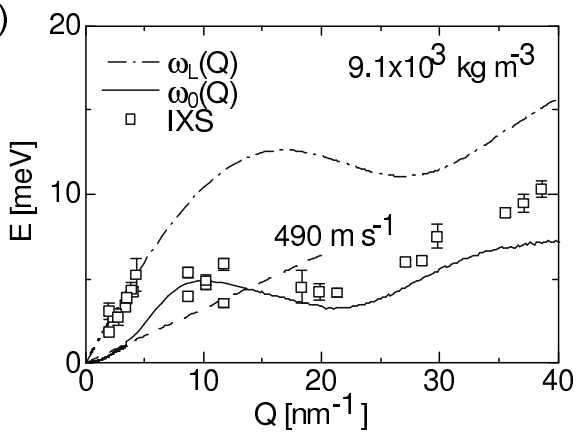

(d)

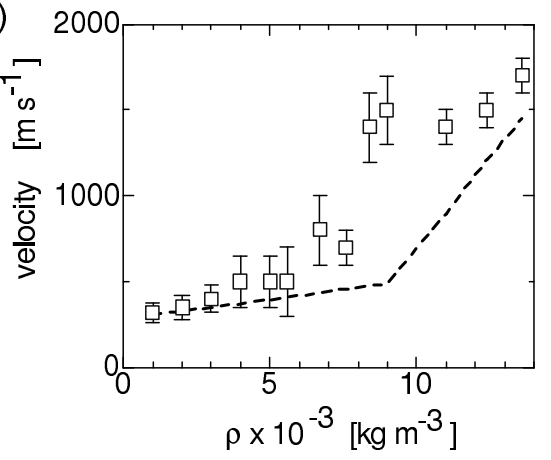

Figure 5. (a) a phase diagram of fluid $\mathrm{Hg}$ on the pressure-temperature plane. A broken line denotes the saturated vapor pressure curve and a solid circle at the end is the critical point. The isochore is denoted by solid lines. The M-NM transition occurs at the isochore of $9 \times 10^{3} \mathrm{~kg} \mathrm{~m}^{-3}$ denoted by a bold solid line. (b) $S(Q, E) / S(Q)$ in the M-NM transition. Circles and bold solid lines denote the experimental data and the model function convoluted by the resolution function, respectively. Also shown are the model function (broken line) and the inelastic component of the collective excitation (solid line). A chain curve at the bottom denotes the resolution function. (c) $E-Q$ dispersion in the M-NM transition in fluid Hg. (d) Dynamical sound velocity (squares) as a function of density. Also shown is the adiabatic sound velocity (a broken line). 
figure exhibits a heavily damped behavior. This behavior suggests a much shorter lifetime of the propagating mode in the M-NM transition and may be related to a large ultrasonic absorption observed in the M-NM transition region [19]. However, the current-current correlation function deduced from the optimized model function exhibits a broad maximum around the excitation energy of the DHO component [20] and we could identify it as a function of $Q$. Figure 5 (c) shows $E-Q$ dispersion in the M-NM transition. The excitation energy (denoted by open squares) disperses triple faster than the adiabatic sound velocity [21] denoted by a broken line. Here we refer to this behavior as "fast sound". Interestingly, the excitation energy at $Q>10 \mathrm{~nm}^{-1}$ approximately follows the normalized second frequency moment $\omega_{0}$ denoted by a solid curve in the figure. Figure 5 (d) shows the dynamical sound velocity deduced from the excitation energy at low $Q$ in the fluid $\mathrm{Hg}$ at various densities. As seen in the figure, the adiabatic sound velocity of the fluid $\mathrm{Hg}$ decreases linearly from $1500 \mathrm{~m} \mathrm{~s}^{-1}$ at the ambient condition with decreasing density while the dynamical one does not change much. As a result, "fast sound" appears in the M-NM transition region. With further volume expansion into the insulating state, the dynamical sound velocity rapidly approaches the adiabatic one. This result suggests that 'fast sound' is a peculiar dynamics in the M-NM transition.

Recently small angle X-ray scattering (SAXS) measurements for expanded fluid Hg were carried out and a new type of fluctuations different from the critical density fluctuation was observed in the M-NM transition [22]. The new fluctuation suggests that the phase separation of metallic and insulating domains occurs in the M-NM transition region, which may be related to a first order M-NM transition predicted by Landau and Zeldovich [23]. To relate the SAXS results to the IXS ones, the normalized fourth frequency moment, $\omega_{\mathrm{L}}$, was calculated from the effective pair potential obtained from $S(Q)$ in the M-NM transition [24,22], as denoted by a chain curve in figure 5 (c). The excitation energy obtained from IXS follows $\omega_{\mathrm{L}}$ at low $Q$. This fact suggests that 'fast sound' in the M-NM transition is regarded as the high-frequency sound speed defined in the viscoelastic theory [25] which will appear in the simple Debye approximation if $\omega \tau \gg 1$ is satisfied, where $\omega$ is the angular frequency of the collective mode and $\tau$ is the relaxation time. The present IXS results suggest that the hydrodynamic to viscoelastic transition occurs at very low $Q$ and very long time that cannot be accessed by IXS. The estimation from the excitation energy at $2 \mathrm{~nm}^{-1}$ in figure 5 (c) allows $\tau$ much longer than 0.8 ps. Since the relaxation process of the high-frequency sound mode is strongly correlated with the persistency of the domains in the M-NM transition, the lifetime of the domains is considered to be much longer than $1 \mathrm{ps}$. Thus, the $\mathrm{M}-\mathrm{NM}$ transition in the fluid $\mathrm{Hg}$ has been found to include very interesting physics from the present structural studies. It is a future subject to clarify how the "fast sound" observed by IXS is correlated with the slow dynamics reported based on the ultrasonic absorption measurements [19].

\subsection{A preliminary result of expanded fluid Se}

Liquid Se has a twofold coordinated chain structure where the atoms are covalently bonded. It experiences a semiconductor-metal-insulator (SC-M-I) transition in an expanded fluid state around the critical point. Figure 6 (a) shows the phase diagram of fluid Se on the pressure-temperature plane. The first indication of the SC-M transition in fluid Se was found in the electrical conductivity data by Hoshino et al. [6], which increases with the increasing temperature from the melting temperature as seen in figure 6 (a). Many experimental studies on the SC-M transition in the expanded fluid Se have been carried out and the early studies are cited in the literature [26]. As far as a sign of the volume contraction accompanying the SC-M transition was observed, the formation of defects such as three-fold coordinated centers in the branched chain as assumed by Cabane and Friedel [27] was expected. However, results of neutron diffraction experiments [28] did not give a significant concentration of threefold-coordinated sites up to $1673 \mathrm{~K}$ and 26.5 MPa. Tamura and Hosokawa [29] carried out x-ray diffraction measurements for expanded fluid Se up to the metallic region and found that the two-fold coordinated structure is largely preserved in the metallic state while the covalent bond becomes slightly short in the SC-M transition. X-ray diffraction measurements of expanded fluid Se were carried out up to the vapor phase consisting of dimeric molecules using synchrotron radiation at Spring-8 in Japan, and the previous results were confirmed by much improved data [30]. 
(a)

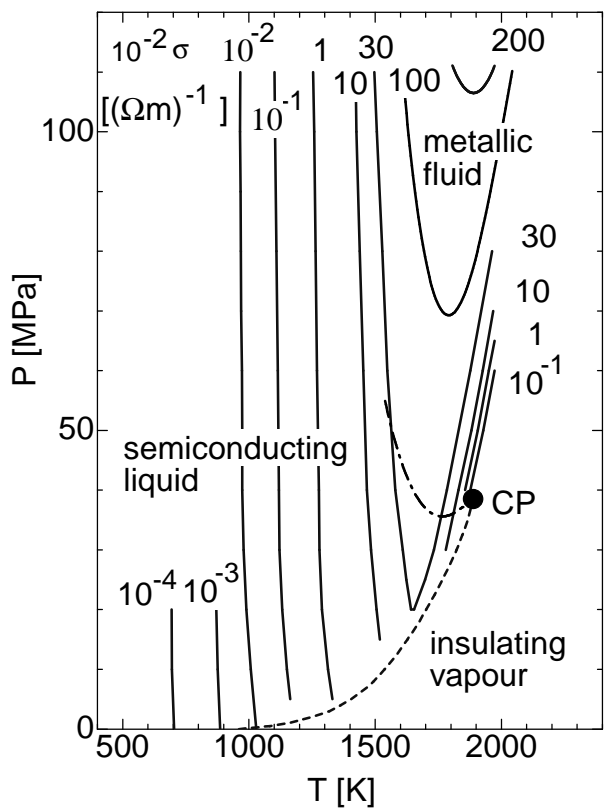

(b)

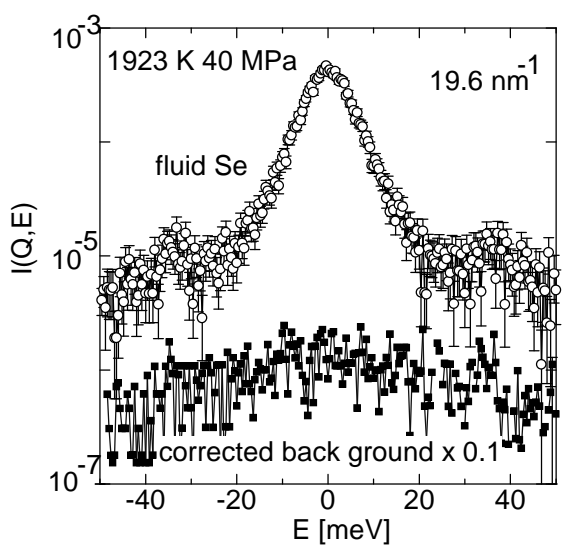

Figure 6. (a) a phase diagram of fluid Se on the pressure-temperature plane. A broken line denotes the saturated vapor pressure curve and a solid circle at the end is the critical point. The contour denoted by solid lines indicates the constant $\mathrm{d} c$ conductivity. The SC-M transition occurs at the constant $\mathrm{d} c$ conductivity of $30 \times 10^{2}(\Omega \cdot m)^{-1}$. A chain curve denotes the thermodynamic states where the optical gap disappears [26]. (b) A semi-log plot of $I(Q, E)$ at $1923 \mathrm{~K}$ and $40 \mathrm{PMa}$ in the vapor phase. Open circles and solid squares connected by a solid line denote the experimental data of fluid Se and the background, respectively. $I(Q, E)$ of the background corrected by the sample absorption is reduced by 0.1 to clarity.

The SC-M transition in fluid Se has two characteristic features. Firstly, the transition occurs with volume expansion at a constant pressure. Secondly, the transition promotes the increase of very short chains and it seems to be correlated with the instability of the chain structure. Recent molecular dynamics simulations [31-33] have clarified the microscopic structure in the SC$\mathrm{M}$ transition in the expanded fluid Se. However, there remains a question why the volume tends to contract in the SC-M transition, because the simulation assumed the temperature dependence of the density experimentally determined. Recently SAXS measurements were reported [34] for expanded fluid Se that were carried out in order to observe the medium-range structure and characteristic fluctuations in the SC-M transition.

To better understand the SC-M transition in expanded fluid Se, the information on atomic dynamics in the fluid is important. In order to observe $S(Q, E)$ the expanded fluid Se, IXS measurements have been carried out using the present high-pressure technique. Figure 6 (b) shows IXS spectrum $I(Q, E)$ of the fluid Se in the vapor phase together with the background. Besides the central component, the excitations at around $35 \mathrm{meV}$ are clearly observed, which will be assigned to the stretching mode of a Se dimeric molecule. Recently, peculiar dynamics in a covalent liquid including the stretching mode was reported in an IXS study for polymeric liquid Se at the ambient condition [35]. Further investigations on collective dynamics in the SC-M transition in expanded fluid Se are now in progress. 


\section{Summary}

In this article we describe the experimental technique for IXS studies of supercritical metallic fluids at high temperature and at high pressure. The high-pressure gas apparatus restricted by the Japanese law may have some overspecifications but it is the only device to study atomic dynamics in supercritical metallic fluids at the present stage. The apparatus was applied to IXS measurements of supercritical fluid $\mathrm{Hg}$ and Se. In the near future, we will develop a new high-pressure vessel with wide windows for scattered X-rays to investigate the atomic dynamics in expanding fluid alkali metals with lower critical pressures, which were recently reported to exhibit a peculiar structural and electronic properties at high temperature and high pressure [36,37].

\section{Acknowledgements}

The authors would like to thank Dr. Y. Tanaka, Dr. S. Tsutsui and Dr. Y. Kajihara for the valuable discussion. The installation of the high-pressure gas apparatus was approved by the organizers at SPring-8. The authors would like to thank many graduate school students in Kyoto University and Hiroshima University for their experimental support. Kobe Steel Co., Ltd. and High Pressure System Co., Ltd. are acknowledged for the technical support about the present experiments. This work was supported by the Grant-in-Aid for Specially Promoted Research from the Ministry of Education, Science and Culture of Japan under contract No. 11102004. The synchrotron radiation experiments were performed at the SPring-8 with the approval of the Japan Synchrotron Radiation Research Institute (JASRI) (Proposal No.2003A6607-LD-np and 2006A1273).

\section{References}

1. Sette F., Ruocco G., Kirsch M., Bergmann U., Masciovecchio C., Mazzacurati V., Signorelli G., Verbeni R., Phys. Rev. Lett., 1995, 75, 850.

2. Burkel E., Rep. Prog. Phys., 2000, 63, 171.

3. Scopigno T., Ruocco G. and Sette F., Rev. Mod. Phys., 2005, 77, 881.

4. Hensel F., Warren W.W. Fluid Metals. Princeton University Press, New Jersey, 1999.

5. Hensel F., Franck E.U., Ber. Bunsenges. Phys. Chem., 1966, 70, 1154.

6. Hoshino H., Schmutzler R.W., Hensel F., Ber. Bunsenges. Phys. Chem., 1976, 80, 27; Hoshino H., Schmutzler R.W., Warren W.W., Hensel F., Philos. Mag., 1976, 33, 255.

7. Winter R., Bodensteiner T., Gläser W., Hensel F., Ber. Bunsenges. Phys. Chem., 1987, 91, 1327; Franz G., Freyland W., Gläser W., Hensel F. and Schneider E., J. Phys. Coll. (Paris), 1980, C8, 194; Winter R., Pilgrim C., Hensel F., Morkel C. and Gläser W., J. Non-Cryst. Solids, 1993, 156-158, 9.

8. Tamura K. and Hosokawa S., J. Physique Coll. IV, C5, 1991, 1, 39.

9. Tamura K., Inui M., J.Phys.: Condens. Matt., 2001, 13, R337.

10. Jüngst S., Knuth B., Hensel F., Phys. Rev. Lett., 1985, 55, 2160.

11. Götzlaff W., Schönherr G., Hensel F., Z. Phys. Chem., Neue Folge, 1988, 156, 219; Götzlaff W., Ph.D. thesis, University of Marburg, 1988.

12. Hosokawa S., Kuboi T., Tamura K, Ber. Bunsenges. Phys. Chem., 1997, 101, 120.

13. Fischer R., Schmutzler W., Hensel F., Ber. Bunsenges. Phys. Chem., 1982, 86, 546.

14. Wagner W., Pruß, J. Phys. Chem. Ref. Data, 2002, 31, No. 2, 387.

15. Baron A.Q.R., Tanaka Y., Goto S., Takeshita K., Matsushita T. and Ishikawa T., J. Phys. Chem. Solids, 2000, 61, 461.

16. Tamura K., Inui M., Hosokawa S., Rev. Sci. Instrum., 1999, 70, 144 .

17. Sutter J.P., et al, unpublished.

18. Ishikawa D., Inui M., Matsuda K., Tamura K., Tsutsui S., Baron A.Q.R., Phys. Rev. Lett., 2004, 93, 097801; Inui M., Ishikawa D., Matsuda K., Tamura K., Tsutsui S. and Baron A.Q.R., J. Phys. Chem. Solids, 2005, 66, 2223.

19. Kohno H., Yao M., J. Phys.: Condens. Matter, 2001, 13, 10293.

20. Tamura K., Inui M., Matsuda K., Ishikawa D., J. Non-Cryst. Solids, 2007, 353, 3348.

21. Yao M., Okada K., Aoki T., Endo H., J. Non-Cryst. Solids, 1996, 205-207, 274; Kozhevnikov V., Arnold D., Grodzinskii E., Naurzakov S., J. Non-Cryst. Solids, 1996, 205-207, 256 .

22. Inui M., Matsuda K., Ishikawa D., Tamura K., Ohishi Y., Phys. Rev. Lett., 2007, 98, 185504. 
23. Landau L., Zeldovich G., Acta Phys. Chem. USSR, 1943, 18, 194.

24. Inui M., Hong X., Tamura K., Phys. Rev. B, 2003, 68, 094108.

25. Boon J. P., Yip S. Molecular Hydrodynamics. McGraw-Hill, New York, 1980

26. Tamura K., J. Non-Cryst. Solids, 1996, 205-207, 239 and references therein.

27. Cabane B., Friedel J., J. Phys. (Paris), 1971, 32, 73.

28. Edeling M., Freyland W., Ber. Bunsenges. Phys. Chem., 1981, 85, 1049.

29. Tamura K., Hosokawa S., Ber. Bunsenges. Phys. Chem., 1992, 96, 681.

30. Inui M., Hong X., Matsusaka T., Ishikawa D., Kazi M. H., Tamura K., Funakoshi K., Utsumi W., J. Non-Cryst. Solids, 2002, 312-314, 274.

31. Shimojo F., Hoshino K., Watabe M., Zempo Y., J. Phys.: Condens. Matter, 1998, 10, 1199.

32. Kirchhoff F., Kresse G., Gillan M. J., Phys. Rev. B, 1998, 57, 10482.

33. Raty J. Y., Gasperd J. P., Bichara C., Phys. Rev. B, 1999, 60, 2441.

34. Inui M., Matsuda K., Tamura K., Satoh K., Sobajima A., Tada H., Journal of Applied Crystallography, 2007, 40, s537.

35. Inui M., Hosokawa S., Matsuda K., Tsutsui S., Baron A.Q.R., J. Phys. Soc. Jpn., 2007, 76, 053601.

36. Pilgrim W.C., Ross M., Yang L.H., Hensel F., Phys. Rev. Lett., 1997, 78, 3685.

37. Matsuda K., Tamura K., Inui M., Phys. Rev. Lett., 2007, 98, 096401.

\title{
Експериментальні методики вимірювань непружнього розсіяння рентгенівських променів високої роздільної здатності для надкритичних металічних плинів при високих температурах та високих тисках використовуючи синхротронну радіацію на SPring-8
}

\author{
М.Інуїํㅛ , Д.Ішікава ${ }^{2}$, К.Мацуда ${ }^{3}$, К.Тамура ${ }^{3}$, А.К.Р.Бейрон ${ }^{2,4}$ \\ ${ }^{1}$ Коледж мистецтва та науки, Університет Хіросіми, Хіросіма, Японія \\ 2 SPring-8/RIKEN, Хіоґо, Японія \\ 3 Інженерний коледж, Університет Кіото, Кіото, Японія \\ 4 SPring-8/JASRI, Хіоґо, Японія
}

Отримано 2 листопада 2007 р.

\begin{abstract}
Нами проведено вимірювання непружнього розсіяння рентгенівських променів високої роздільної здатності для надкритичних металічних плинів при високих температурах та високих тисках 3 використанням синхротронної радіації на SPring-8 у Японії. Ми розробили комірку високого тиску для вимірювання непружнього розсіяння рентгенівських променів, що дозволяє нагнітати тиск за допомогою гелієвого газу аж до 196 МПа та інсталювали апарат газу високого тиску в екпериментальний бункер. Після інсталяції були проведені експерименти по непружньому розсіянню рентгенівських променів для надкритичної рідкої ртуті, щоб дослідити атомну динаміку при переході метал-неметал біля критичної точки рідина-газ. Пізніше апарат використовується для дослідження атомної динаміки при переході напівпровідник-метал у надкритичному плині селену. У цій статті ми описуємо експериментальну методологію при високій температурі та високому тиску, та наводимо недавні результати з використанням цієї методики.
\end{abstract}

Ключові слова: надкритичні металічні плини атомна динаміка, непружне розсіяння рентгенівських променів, високі температури, високі тиски, рідка ртуть

PACS: $61.25 . M v, 61.10 . E q, 71.30 .+h, 63.50 .+x, 47.35 . R s, 51.40 .+p$ 
